Disponível em

http://www.anpad.org.br/rac

RAC, Rio de Janeiro, v. 19, n. 5, art. 2, pp. 565-583, Set./Out. 2015 http://dx.doi.org/10.1590/1982-7849rac20151626

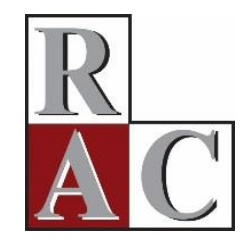

\title{
Empreendedorismo Religioso: Um Estudo sobre Empresas que Exploram o Nicho da Religiosidade
}

Religious Entrepreneurship: A Study of Businesses that Explore the Religiosity Niche

\author{
Alex Fernando Borges \\ Universidade Federal de Uberlândia - UFU \\ Alessandro Gomes Enoque \\ Universidade Federal de Uberlândia - UFU \\ Jacquelaine Florindo Borges \\ Universidade Federal de Uberlândia - UFU \\ Lorrana Laila Silva de Almeida \\ Universidade Federal de Uberlândia - UFU
}

Artigo recebido em 01.09.2013. Última versão recebida em 03.11.2014. Aprovado em 04.11.2014. 


\title{
Resumo
}

O objetivo deste trabalho consistiu em compreender as particularidades da manifestação do empreendedorismo religioso em empresas que nascem no contexto da religião e comercializam artigos religiosos. A partir de um quadro teórico que articula as definições de empreendedorismo e processo empreendedor, e que estabelece relações entre empreendedorismo e religião, foram estudadas, por meio de pesquisa qualitativa, 22 empresas que comercializam produtos de diferentes denominações religiosas, situadas nas três maiores cidades da região do Triângulo Mineiro. Os resultados mostram a manifestação de um tipo particular de empreendedorismo, observado através das seguintes categorias: o empreendedor religioso, envolvendo a análise da ideia e das motivações individuais para a abertura da empresa; a religião enquanto oportunidade de negócio, envolvendo a análise do contexto e dos aspectos religiosos e comerciais que influenciam o processo do empreendedorismo religioso; e os resultados desta ação empreendedora, envolvendo os efeitos concretos e simbólicos do empreendedorismo religioso.

Palavras-chave: empreendedorismo; processo empreendedor; empreendedorismo religioso; religião.

\begin{abstract}
The purpose of this paper consisted of comprehending the particularities of religious entrepreneurship concerning businesses that emerge in a religious context and sell religious products. Based on a theoretical framework that articulates both entrepreneurship and entrepreneurial process definitions, and that establishes relationships between entrepreneurship and religion, 22 businesses that sell products from various religious denominations located in the three largest cities of the Triângulo Mineiro region were studied through qualitative research. The results show the manifestation of a particular type of entrepreneurship, associated with the following categories: the religious entrepreneur, involving the analysis of ideas and individual motivations for business creation; religion as business opportunity, involving the analysis of contextual, religious and business aspects that influence religious entrepreneurship; and the results of those entrepreneurial actions, involving concrete and symbolic effects of religious entrepreneurship.
\end{abstract}

Key words: entrepreneurship; entrepreneurial process; religious entrepreneurship; religion. 


\section{Introdução}

O empreendedorismo se constitui como um fenômeno de interesse crescente por parte de agentes da comunidade acadêmica e do mercado, uma vez que gera importantes repercussões em termos de geração de emprego e renda. Esse fenômeno tem sido objeto de problematização científica, na medida em que se torna necessário compreender suas especificidades e possibilidades de manifestação (Busenitz et al., 2003).

A pesquisa sobre empreendedorismo tem sido explorada através de perspectivas variadas. A amplitude do campo pode ser observada a partir da diversidade de pesquisas, trabalhos científicos, periódicos e eventos especializados. Dentre os tópicos mais estudados, destacam-se a criação de novos negócios, o perfil e o comportamento empreendedor, oportunidades, intraempreendedorismo, inovação e risco (Filion, 1999a). Mais recentemente, temáticas como o empreendedorismo social (Certo \& Miller, 2008), a orientação empreendedora (Rauch, Wiklund, Lumpkin, \& Frese, 2009) e o empreendedorismo cultural (Hayton, George, \& Zahra, 2002) tem se estabelecido como novas direções de pesquisas que contribuem para uma melhor compreensão do fenômeno empreendedor.

O presente trabalho atribui atenção especial à interação entre empreendedorismo e questões associadas ao campo religioso. Evidências iniciais dessa interação podem ser identificadas na obra do sociólogo Max Weber, em seu livro Ética Protestante e o Espírito do Capitalismo. Weber (2001) via os capitalistas (empreendedores) como indivíduos inovadores e independentes, cujo papel de liderança nos negócios advinha de um sistema de valores marcado por uma ética protestante (Filion, 1999b; Martes, 2010). Assim, as diferenças na atividade empreendedora poderiam ser explicadas por fatores culturais e religiosos (Zelekha, Avnimelech, \& Sharabi, 2014).

Diversos pesquisadores apontaram evidências sobre o papel e a influência da religião sobre a atividade empreendedora (Carswell \& Rolland, 2004, 2007; Dana, 2009, 2010; Dougherty, Griebel, Neubert, \& Park, 2013; Drakopoulou Dodd \& Gotsis, 2007; Drakopoulou Dodd \& Seaman, 1998; Jackson \& Konz, 2006; Kauanui, Thomas, Sherman, Waters, \& Gilea, 2008; Martes \& Rodriguez, 2004; Zelekha et al., 2014). Apesar desses esforços, a relação entre religião e empreendedorismo ainda é pouco compreendida cientificamente. Existe um número limitado de estudos sobre a temática, refletindo um quadro teórico subdesenvolvido, fato que indica a necessidade de outros estudos teóricos e empíricos que explorem essa relação (Tracey, 2012; Zelekha et al., 2014).

Sendo assim, este artigo procura contribuir para a compreensão de um tipo particular de fenômeno empreendedor - caracterizado como empreendedorismo religioso - identificado através da influência de elementos simbólicos e subjetivos do campo da religião em decisões e ações de criação de novos negócios, no processo de identificação de oportunidades e sua exploração, na adoção de inovações e novas práticas organizacionais, e na condução das atividades do empreendimento. Evidentemente, esse tipo de empreendedorismo se manifesta de forma ainda mais efetiva no âmbito de empresas que atuam na mercantilização de produtos e artigos religiosos, nos quais a religião se posiciona como motivação e até mesmo oportunidade para a criação de novos negócios. Neste estudo, busca-se explorar este nicho de mercado pouco estudado na academia, caracterizado pela comercialização de produtos que trazem consigo um conjunto de significados e símbolos que se associam a componentes religiosos.

Com base em tal conjunto de evidências, questiona-se: como ocorre a manifestação do empreendedorismo religioso em empresas que exploram o nicho da religiosidade através da comercialização de produtos e artigos religiosos? Para responder a esse questionamento, o objetivo do presente trabalho consiste em compreender as particularidades da manifestação do empreendedorismo religioso a partir do estudo de organizações que nascem no contexto da religião e que comercializam artigos religiosos na região do Triângulo Mineiro, Minas Gerais. Especificamente, busca-se identificar as particularidades do processo empreendedor nas empresas estudadas, abrangendo aspectos como o surgimento da ideia, as oportunidades no setor, a exploração dessas oportunidades e as motivações para a criação do negócio, a decisão de abertura da empresa e os objetivos religiosos e comerciais intervenientes a esse processo. 
O artigo é organizado como segue: primeiro, serão apresentados conceitos e abordagens associados ao fenômeno do empreendedorismo; segundo, serão demonstradas relações entre empreendedorismo e religião, e, posteriormente, serão expostos os procedimentos metodológicos; terceiro, serão apresentados e discutidos os resultados da pesquisa; por fim, serão apontadas algumas conclusões do estudo, bem como limitações e sugestões de pesquisas futuras.

\section{O Fenômeno do Empreendedorismo}

A produção científica sobre empreendedorismo tem procurado estabelecer as fronteiras teóricas desse fenômeno. Incluem-se, nesse movimento de pesquisa, a busca pela delimitação de conceitos como empreendedorismo e empreendedor, pela demarcação de seus tipos específicos, e pela compreensão de suas características e de sua manifestação. Não obstante, uma análise mais aprofundada da literatura permite verificar que não há, atualmente, consenso em termos de definições e quadros teóricos que tenham potencial para explicar as particularidades associadas ao empreendedorismo (Grégoire, Noël, Déry, \& Béchard, 2006).

A evolução do campo de estudos sobre empreendedorismo possibilita a identificação de diferentes correntes de pesquisa, as quais procuram elucidar aspectos importantes que permitem compreender a configuração do referido fenômeno. Uma das correntes de pesquisa defende que o empreendedorismo pode ser explicado através da concepção de processo empreendedor. Jack e Anderson (2002) apontam que essa abordagem busca abandonar a análise isolada do indivíduo empreendedor, passando a visualizar o empreendedorismo enquanto processo. Para Moroz e Hindle (2012), a visão de empreendedorismo como processo constitui uma corrente teórica que permite a análise de múltiplas perspectivas que delimitam-no. Por fim, a referida abordagem ajudaria no reconhecimento de fatores necessários, inclusive, à própria definição de empreendedorismo: "como, por quem, e com quais efeitos as oportunidades de criação de produtos e serviços são descobertas, avaliadas e exploradas" (Shane \& Venkataraman, 2000, p. 218).

A visão do empreendedorismo como processo tem sido alvo de pesquisadores que procuram compreender a manifestação desse fenômeno para além do enfoque comportamental. Para Shane e Venkataraman (2000), o empreendedorismo pode ser visualizado como um processo empreendedor, o qual envolveria características pessoais e contextuais, a existência de oportunidades, sua identificação e exploração (em suas diferentes possibilidades), e a execução do empreendimento. Bygrave (2008) afirma que o processo empreendedor abrange todas as funções, atividades e ações associadas com a percepção de oportunidades e com a posterior criação de negócios para aproveitá-las. Para o autor, o êxito do processo empreendedor reside no reconhecimento das capacidades empreendedoras do indivíduo e na influência exercida por um conjunto de fatores que limitam, restringem e conformam as atividades empreendedoras. Já o estudo de Jack e Anderson (2002) aponta para a necessidade de se analisar, em uma mesma perspectiva, o papel desempenhado pelo agente empreendedor e a influência de aspectos contextuais, mutuamente configurando possibilidades de processos empreendedores. Por fim, Haber e Reichel (2007) argumentam que o processo empreendedor engloba etapas cumulativas de recursos que convergem para a criação de um novo negócio, envolvendo uma ideia, seguida de um estudo de viabilidade do conceito do negócio, do estabelecimento do empreendimento e de sua posterior abertura e operação. Sendo assim, cabe explorar, rapidamente, cada uma dessas concepções, visando compreender adequadamente a manifestação do processo empreendedor em organizações.

Inicialmente, as discussões sobre o processo empreendedor envolvem a ação de indivíduos empreendedores. Jack e Anderson (2002) apontam que os agentes empreendedores seriam responsáveis por moldar processos de criação de novos negócios através de suas ideias e motivações. Hessels, Gelderen e Thurik (2008) valorizam o papel desempenhado pelas motivações dos empreendedores na orientação e no direcionamento de processos de abertura de empresas. Por fim, Nassif, Ghobril e Silva (2010) ressaltam que o enfoque nos atributos pessoais dos empreendedores contribui para a compreensão de aspectos afetivos e cognitivos que influem sobre o processo empreendedor. 
Adicionalmente, a análise do processo empreendedor passa pela compreensão do conceito de oportunidades. Oportunidades empreendedoras são situações em que novos produtos, serviços e métodos de organização, podem ser introduzidos e comercializados gerando lucros, podendo ser identificadas ou criadas pelo empreendedor, que conhece e/ou observa o mercado (Mcmullen, Plummer, \& Acs, 2007; Shane \& Venkataraman, 2000; Short, Ketchen, Shook, \& Ireland, 2010). Para Short, Ketchen, Shook e Ireland (2010), uma oportunidade consiste em uma ideia que é descoberta ou criada por uma entidade empreendedora, e que se revela como potencialmente lucrativa ao longo do tempo. As oportunidades empreendedoras surgem de variadas fontes emergentes e/ou inexploradas (Plummer, Haynie, \& Godesiabois, 2007; Shane, 2000), sendo transformadas em produtos, serviços ou práticas inovadoras (Buenstorf, 2007). Tal análise também evidencia outra problemática, na medida em que o empreendedorismo poderia ocorrer de modo pró-ativo, a partir da busca de oportunidades de negócio, ou de modo reativo, através de necessidades por trabalho e renda (Souza, 2005).

Sendo assim, para Shane e Venkataraman (2000) e para Eckhardt e Shane (2003), somente haveria empreendedorismo na medida em que existissem oportunidades empreendedoras. De acordo com os autores, o empreendedorismo abarca duas dimensões distintas, porém, complementares: (a) a presença de oportunidades lucrativas; e (b) a presença de indivíduos dispostos a empreender. Para Shane e Venkataraman (2000), o processo de descoberta de oportunidades envolve a posse de informações e uma análise criteriosa do contexto, possibilitando, com isso, sua identificação e posterior exploração. Assim, mesmo indivíduos com experiência e/ou conhecimento de mercado, com capacidade para identificar oportunidades de negócio, necessitariam de uma habilidade interna para identificar tais oportunidades. Portanto, o processo de exploração de oportunidades seria influenciado por características individuais e contextuais, em uma relação dialógica (Plummer et al., 2007).

A concepção de ação empreendedora emerge, então, no bojo das discussões sobre o processo empreendedor (Lima, 2010). De acordo com Watson (2013), a ação empreendedora pode ser vista como uma categoria de criatividade situada. De acordo com essa perspectiva, agir de forma empreendedora significa inovar, lidar com situações sociais e econômicas e com situações que limitam e facilitam a definição de ações empreendedoras e de seus resultados (Watson, 2013). Para Gomes, Lima e Cappelle (2013), a ação empreendedora envolve a produção de inovações radicais e/ou incrementais a partir de uma perspectiva multidimensional, envolvendo o empreendedor, a empresa e o ambiente. $\mathrm{O}$ foco nas ações empreendedoras apresenta-se como alternativa para a realização de estudos sobre o empreendedorismo, permitindo a apreensão de elementos econômicos, sociais e culturais intervenientes a esse fenômeno. Considera-se neste trabalho que a concepção da ação empreendedora constitui perspectiva sintetizadora do processo empreendedor, uma vez que os eventos associados ao referido processo passam pela agência de indivíduos empreendedores. Ao mesmo tempo, os resultados da ação empreendedora se manifestam tanto na construção e na criação de novos negócios, como na configuração de novos produtos, serviços, atividades e práticas, contribuindo para a renovação de organizações (Gomes, Lima, \& Cappelle, 2013; Lima, 2010).

O conjunto de evidências teóricas apresentado oferece alternativas para a análise e compreensão do fenômeno do empreendedorismo. Neste sentido, no próximo tópico, serão discutidas as possibilidades de associação entre empreendedorismo e religião, buscando contribuir para o avanço das pesquisas sobre a temática.

\section{Empreendedorismo e Religião}

O interesse pelo componente cultural é crescente nos estudos sobre empreendedorismo (Hayton $e t$ al., 2002; Silva, Gomes, \& Correia, 2009). As pesquisas que abordam essa relação procuram compreender e verificar a influência de aspectos como valores, símbolos e comportamentos sobre a atividade empreendedora. Por sua vez, certos valores culturais se associam a aspectos ligados à religião. Dana (2009) afirma que a religião imprime características específicas em iniciativas empreendedoras, uma vez que a mesma ensina, promove e propaga um sistema de valores em uma dada sociedade (Dana, 2009). 
Os trabalhos de Max Weber (2001) apresentam amparo teórico significativo para se compreender a relação entre empreendedorismo e religião. A partir de estudos acerca da influência dos fatores culturais e, principalmente, do ethos religioso sobre a dinâmica da atividade econômica, Weber (2001) defendia que o protestantismo se estruturava através de uma ética teologicamente inovadora. Ao desenvolver a noção de santidade do chamado para o mundano e para o trabalho mundano, Weber (2001) destacou o papel e a responsabilidade dos membros leigos da igreja, que estimulavam e valorizavam o ceticismo enquanto elemento responsável pela formação de um processo de acumulação de capital (Drakopoulou Dodd \& Gotsis, 2007). O capitalista empreendedor weberiano seria, então, um agente relativamente distinto, caracterizado pela busca do ganho econômico, pela tolerância ao risco, pela subordinação do consumo sobre a acumulação (Martinelli, 1995), e pela aceitação do trabalho ético protestante (Zelekha et al., 2014).

A análise efetuada por Weber vem sendo ampliada nas últimas décadas, e indica diferentes possibilidades para a relação entre empreendedorismo e religião. Carswell e Rolland (2004) afirmam que há, atualmente, uma diversidade étnica e religiosa cada vez maior, exercendo influências distintas sobre o empreendedorismo. Diante disso, verifica-se que os valores religiosos agem sobre o comportamento dos indivíduos gerando um efeito direto sobre suas motivações e ações, influindo na propensão ao empreendedorismo e no processo empreendedor (Dana, 2010; Drakopoulou Dodd \& Gotsis, 2007). Assim, a relação entre empreendedorismo e religião tem sido explorada não somente no âmbito do Protestantismo (Becker \& Woessmann, 2009; Carswell \& Rolland, 2007; Light, 2010), mas também no contexto do Catolicismo (Cornwall \& Naughton, 2003), do Judaísmo (Weinfeld, 2010), do Budismo (Collins, 1997), do Hinduísmo (Audretsch \& Meyer, 2009) e do Islamismo (Ghoul, 2010; Nekka \& Fayolle, 2010). Cabe ressaltar ainda que, de acordo com Zelekha, Avnimelech e Sharabi (2014), existem evidências de que as diferentes religiões possuem distintas possibilidades de influência sobre o empreendedorismo.

Dana (2009) apresenta algumas delimitações que explicitam a maneira como a religião se relaciona ao empreendedorismo: (a) as diferentes religiões valorizam o empreendedorismo de formas distintas; (b) as diversas religiões produzem diferentes padrões de comportamento empreendedor, devido a diferenças em seus conjuntos de valores; (c) a especialização em uma determinada religião determina o empreendedorismo; (d) as redes de relacionamento entre membros de uma determinada religião delimitam o empreendedorismo; (e) a religião oferece oportunidades empreendedoras; (f) as crenças religiosas podem dificultar o empreendedorismo; e $(\mathrm{g})$ as religiões possuem mecanismos para a perpetuação de valores que facilitam ou dificultam o empreendedorismo.

Drakopoulou Dodd e Gotsis (2007), por sua vez, procuraram desenvolver um quadro teórico para explicar a relação entre empreendedorismo e religião, por meio de uma abordagem multinível. No nível individual (micro), os autores afirmam que o conteúdo, a importância e os componentes sociais da religião influenciam o empreendedor, inserindo-o no meio sociocultural. Tal influência, por sua vez, se dá por meio de impactos sobre o comportamento do indivíduo e a natureza de sua decisão ética, sobre o estado psicológico do empreendedor, seu papel social e a rede de relacionamentos na qual se insere, sobre sua origem étnica e seu nível educacional, bem como sobre objetivos e limitações estratégicas, acerca do estilo de liderança e, até mesmo, de sua propensão ao risco e de seu desempenho. No nível contextual (macro), aspectos sociais, éticos, organizacionais e econômicos, a cultura nacional, bem como o apoio e/ou a proibição da atividade empreendedora parte da religião exercem impactos importantes sobre o empreendedorismo.

Para Drakopoulou Dodd e Gotsis (2007), existem evidências de que a religião exerce algumas influências específicas sobre o processo empreendedor, presentes em três momentos distintos: (a) na aquisição de motivação para a abertura do empreendimento, fornecendo ou fundamentando o desejo do empreendedor e sua motivação; (b) nas negociações efetuadas para a entrada no mundo empresarial, oferecendo uma espécie de comunidade integrada na qual o empreendedor pode adquirir os recursos necessários para iniciar suas atividades; e (c) no âmbito do nascimento da empresa e sua sobrevivência, estimulando um foco eticamente coerente, compartilhado e de longo prazo, para gestão e direção do novo negócio ao longo do tempo. Assim, a religião constituir-se-ia como um fato que delimita preferências éticas do agente empreendedor, influenciando perspectivas de liderança e de tomada de 
decisões estratégicas, e aumentando sua satisfação com a vida e com o trabalho. Ao mesmo tempo, essa relação é mediada por fatores como as estruturas políticas e ideológicas, e como o simbolismo religioso no mundo do trabalho e na educação. Portanto, a influência da religião sobre a tomada de decisão do empreendedor é impactada por sua configuração sociotemporal, pelo conteúdo teológico que eles defendem, pela importância da religião em suas vidas, pelas fontes de autoridades religiosas que eles reconhecem e pelo status social associado à denominação religiosa (Drakopoulou Dodd \& Gotsis, 2007).

O cenário acima apresentado reforça, pois, a necessidade de se buscar explicações adicionais para a relação entre empreendedorismo e religião. Com efeito, a cultura e a religião podem influir sobre a exploração de oportunidades, sobre o desejo e a motivação para a abertura do novo negócio, sobre o risco percebido e sobre os retornos da atividade empreendedora (Drakopoulou Dodd \& Gotsis, 2007; Zelekha et al., 2014). Neste contexto, a produção e a comercialização de produtos religiosos fornecem oportunidades para o empreendedorismo (Dana, 2009). No Brasil, por exemplo, existem cidades que se caracterizam por intensa atividade religiosa (Aparecida, Salvador, Ouro Preto, Congonhas, Uberaba, dentre tantas outras), nas quais se observa um tipo de comércio transitório de artigos religiosos (principalmente quando ocorre nos períodos de festas religiosas). Todavia, pode-se observar que a mercantilização do sagrado alcançou contornos de formalização de atividades e utilização de técnicas gerenciais tradicionais. Tais práticas visam garantir a sobrevivência desses empreendimentos, gerando renda necessária à sobrevivência de empreendedores e de suas famílias, e impulsionando a economia local. Desse modo, essas organizações podem se tornar negócios lucrativos, promissores e sustentáveis ao longo do tempo (Enoque, Borges, Borges, Almeida, \& Mariano, 2014).

Portanto, o empreendedorismo se associa à comercialização de produtos religiosos. Há, evidentemente, uma dinâmica própria, fundamentada na manifestação de um tipo de empreendedorismo que não leva em consideração apenas a questão econômica, mas também o aspecto cultural, simbólico e religioso (Enoque et al., 2014). Sendo assim, este trabalho concentra esforços sobre a configuração do empreendedorismo religioso a partir do estudo de organizações em que a religião se coloca como fator desencadeador de um processo empreendedor marcado por esse tipo particular de empreendedorismo.

\section{Procedimentos Metodológicos}

Nesta pesquisa foi empregada uma abordagem qualitativa de investigação (Denzin \& Lincoln, 2008, 2011), com o intuito de compreender as particularidades do empreendedorismo religioso em empresas que nascem no contexto da religião e que comercializam artigos religiosos. Essa abordagem é apropriada para apreender a dinâmica de um tipo de empreendedorismo revestido por aspectos culturais e simbólicos (Neergaard \& Ulhøi, 2007). A pesquisa de campo, executada no período entre fevereiro e setembro de 2012, foi estruturada com base na estratégia de estudo multicaso (Yin, 2005). Essa estratégia é adequada para descrever dinâmicas atuais e singulares, e para gerar teorias sobre os fenômenos investigados (Eisenhardt, 1989; Eisenhardt \& Graebner, 2007).

Em relação ao público da pesquisa, foi utilizada a estratégia de caso típico, pois o público deste estudo ilustra e representa (Patton, 1990) as particularidades do empreendedorismo religioso que se busca compreender. Inicialmente, buscou-se compor o público da pesquisa a partir de empreendimentos de natureza religiosa situados nas cidades de Uberlândia, Uberaba e Araguari, localizadas na região do Triângulo Mineiro, estado de Minas Gerais. Essas cidades são conhecidas por suas festas religiosas, procissões, grupos populares, folclóricos e de devoção, e por igrejas, centros e templos que fazem parte do patrimônio histórico local e reúnem grande número de fiéis. Ainda, em Uberaba, destaca-se a obra espiritual legada pelo médium Chico Xavier. Nesse sentido, essas cidades retratam uma dinâmica comum a municípios do interior desse e de outros estados do país, associada a uma intensa atividade religiosa que caracteriza não apenas a dinâmica social e cultural dessas localidades, mas também a economia local. Além daquele comércio transitório, que surge em datas de festas religiosas tradicionais, emerge outro tipo de comércio de natureza regular: o comércio de artigos religiosos. Assim, a 
religiosidade que caracteriza essas cidades mineiras foi um aspecto relevante para sua seleção enquanto contexto da pesquisa.

Diante disso, realizou-se uma busca por esses empreendimentos junto a catálogos impressos e eletrônicos, possibilitando a reunião de dados básicos de cada organização (endereço, telefone). Foi efetuado um primeiro contato, visando à confirmação da existência dos mesmos. Nessa etapa, foram excluídas as empresas que não estavam mais em funcionamento e aquelas que eram de propriedade de alguma organização religiosa. Além disso, três gestores não se disponibilizaram a participar da pesquisa (um de cada religião: católica, evangélica, umbanda). Após essas exclusões, respondentes de 22 empresas confirmaram sua participação na pesquisa. Um segundo contato por telefone foi realizado para o agendamento da data e do local da entrevista, as quais foram realizadas nos próprios estabelecimentos. Por fim, ainda em relação aos critérios para a seleção dos casos a serem estudados, buscaram-se empresas em que houvesse a presença de atividade comercial claramente vinculada à comercialização de produtos e artigos religiosos, a presença da figura do empreendedor responsável pela abertura do empreendimento e/ou de pessoas diretamente envolvidas no processo de criação das empresas (no caso de negócios familiares). A Tabela 1 apresenta a caracterização dos empreendimentos estudados.

Tabela 1

\section{Caracterização dos Empreendimentos Estudados}

\begin{tabular}{|c|c|c|c|c|}
\hline Cidade & Casos & $\begin{array}{l}\text { Tempo de funcionamento } \\
\text { da empresa }\end{array}$ & $\begin{array}{l}\text { Gênero dos } \\
\text { respondentes }\end{array}$ & $\begin{array}{l}\text { Produtos vinculados à } \\
\text { religião }\end{array}$ \\
\hline \multirow[t]{8}{*}{ Uberaba } & Empresa 1 & 4 anos & Masculino & Católica \\
\hline & Empresa 2 & 29 anos & Feminino & Católica \\
\hline & Empresa 3 & 11 anos & Feminino & Católica \\
\hline & Empresa 4 & 2 anos & Feminino & Espírita \\
\hline & Empresa 5 & 6 anos & Feminino & Espírita \\
\hline & Empresa 6 & 11 anos & Masculino & Evangélica \\
\hline & Empresa 7 & 30 anos & Feminino & Católica e Umbanda \\
\hline & Empresa 8 & 16 anos & Masculino & Católica e Umbanda \\
\hline \multirow[t]{4}{*}{ Araguari } & Empresa 9 & 8 anos & Masculino & Católica \\
\hline & Empresa 10 & 26 anos & Masculino & Católica \\
\hline & Empresa 11 & 10 anos & Feminino & Católica e Umbanda \\
\hline & Empresa 12 & 8 anos & Feminino & Umbanda e Candomblé \\
\hline \multirow[t]{10}{*}{ Uberlândia } & Empresa 13 & 25 anos & Feminino & Católica \\
\hline & Empresa 14 & 4 anos & Masculino & Católica \\
\hline & Empresa 15 & 27 anos & Feminino & Evangélica \\
\hline & Empresa 16 & 2 anos & Masculino & Evangélica \\
\hline & Empresa 17 & 4 anos & Feminino & Evangélica \\
\hline & Empresa 18 & 25 anos & Feminino & Evangélica \\
\hline & Empresa 19 & 30 anos & Masculino & Umbanda \\
\hline & Empresa 20 & 2 anos & Feminino & Umbanda \\
\hline & Empresa 21 & 22 anos & Feminino & Umbanda \\
\hline & Empresa 22 & 11 anos & Masculino & Espírita \\
\hline
\end{tabular}


Como pode ser observado na Tabela 1, procurou-se compor o público da pesquisa com empresas que comercializam produtos de diferentes doutrinas religiosas. Essa estratégia traz amplitude e variedade para a investigação, uma vez que o estudo de organizações de diferentes dinâmicas contribui para enriquecer o material empírico coletado. Outro aspecto considerado foi o grau de envolvimento dos empreendedores com as respectivas religiões. Dos 22 casos estudados, dois dos entrevistados não possuíam vínculos com as religiões que originaram seus empreendimentos: no caso 19, o empreendedor professa vínculo com a religião espírita; no caso 21, a empreendedora afirma não ter religião, apesar de frequentar igrejas católicas e centros espíritas quando sente vontade. Além disso, nos casos de empresas que atuam com a comercialização de produtos vinculados com religião católica e com a umbanda (casos 7, 8 e 11), os entrevistados apresentam vínculos mais fortes com a umbanda. Tanto nos casos 7,8 e 11 quanto nos casos 19 e 21, há que se levar em consideração o sincretismo entre as religiões, o que faz com que denominações aparentemente contraditórias tenham proximidade importante, não só do ponto de vista da prática religiosa, mas também do ponto de vista comercial, sendo, portanto, objeto de um mesmo negócio.

A partir da seleção dos casos, foram realizadas entrevistas em profundidade junto aos empreendedores, orientadas por um roteiro semiestruturado (Gaskell, 2010). Esse roteiro foi elaborado com questões que buscavam resgatar historicamente o processo de criação das empresas, o surgimento e a identificação da oportunidade, as motivações dos empreendedores, a evolução do negócio ao longo do tempo, assim como compreender o atual estado dos empreendimentos. As entrevistas foram conduzidas face a face, na modalidade presencial, e foram gravadas, após consentimento dos entrevistados. Os pesquisadores tinham liberdade para abordar aspectos emergentes não previstos no roteiro. Ao mesmo tempo, os dados coletados foram comparados ao roteiro de entrevista e aos objetivos da pesquisa, de modo a verificar a consecução dos propósitos da investigação. A saturação dos dados foi observada em certos momentos, sobretudo a partir de uma análise cruzada de casos pertencentes a um mesmo espectro religioso.

Posteriormente, as entrevistas foram transcritas, de modo que as falas pudessem ser recuperadas e analisadas conforme a técnica de análise de conteúdo (Bardin, 2004). O corpus da pesquisa reuniu um material com aproximadamente 22 horas de gravação, com média de 60 minutos por entrevista. As entrevistas cumpriram adequadamente o seu papel de resgatar informações a respeito da dinâmica empreendedora das empresas que comercializam artigos religiosos, uma vez que foi possível obter, em profundidade, narrativas de empreendedores e/ou gestores dessas organizações que vivenciaram esses processos. Mesmo nos casos de empresas com mais de 10 ou 20 anos de existência, foi possível retomar os processos de criação dos negócios estudados, uma vez que estes constituem trajetórias que marcaram, de forma importante, a história de vida dos sujeitos entrevistados. A análise do conteúdo das entrevistas permitiu a identificação de temas e categorias associados à relação entre empreendedorismo e religião, e à dinâmica desse tipo de empreendimento. Na próxima seção, essas categorias serão apresentadas e analisadas e, desse modo, os elementos associados ao empreendedorismo religioso são recuperados a partir do quadro teórico construído.

\section{Empreendedorismo Religioso: Particularidades do Fenômeno}

Nesta seção, serão apresentados e discutidos os resultados da pesquisa de campo, realizada com o propósito de se compreender as particularidades da manifestação do empreendedorismo religioso em empresas que nascem no contexto da religião e comercializam artigos religiosos. De modo geral, as empresas estudadas atuam em um amplo espectro de religiões, quais sejam: católicas (total de 7 empresas); evangélicas (total de 5 empresas); espíritas (total de 3 empresas); e umbanda/candomblé (total de 7 empresas). As organizações pesquisadas comercializam produtos associados a uma ou mais religiões, e foram criadas por empreendedores que possuem vínculos importantes com a doutrina religiosa. A seguir, serão exploradas as possibilidades de manifestação desse fenômeno empreendedor religioso a partir de três categorias de análise vinculadas à concepção de processo empreendedor expostas no referencial teórico deste trabalho: o agente empreendedor; a religião enquanto oportunidade 
de negócio; e os resultados do processo empreendedor. Cabe ressaltar que, por limitações de espaço, serão apresentadas no decorrer da análise somente aquelas narrativas consideradas como mais representativas para as categorias apontadas na metodologia.

\title{
O empreendedor religioso: ideias e motivações para a criação de novos negócios
}

Como exposto, uma das questões que se coloca no âmbito do processo empreendedor encontrase vinculada à ação do sujeito empreendedor, através de uma ideia e de suas motivações para a abertura de um novo negócio (Hessels, Gelderen, \& Thurik, 2008; Jack \& Anderson, 2002; Nassif, Ghobril, \& Silva, 2010). Torna-se relevante, pois, averiguar o papel desempenhado pelos sujeitos no desencadeamento do processo empreendedor e do empreendedorismo religioso, fato gerador da criação e do estabelecimento das empresas estudadas no ramo da religiosidade e da comercialização de artigos religiosos.

Em um primeiro momento, verifica-se a importância do espectro religioso na conformação e no direcionamento do surgimento da ideia para a criação do novo negócio, conforme evidenciado a seguir:

\begin{abstract}
"Surgiu essa ideia assim que a gente converteu, porque a gente não era nada, e só foi aí que a gente teve o encontro com Deus .... [A ideia de abertura da empresa] surgiu através da minha esposa, ela teve essa ideia. A gente começou em casa, numa lojinha em casa mesmo, e lá no fundo de casa a gente tinha um quartinho, e aí a gente começou. E aí, quando o pessoal começou a prestigiar ..., logo foi abrindo as portas, ... e a gente viu um comércio que estava fechado e [resolvemos]: 'vamos fazer uma experiência aqui', 'vamos abrir as portas"”. (Empreendedor - Empresa 6).
\end{abstract}

"Eu faço parte da igreja, eu sou membro do conselho administrativo da igreja. Então, a ideia do negócio nasceu lá dentro, em uma conversa meio que informal. Trabalhei um ano na informalidade, dentro da igreja. E aí, somente em um ano e meio que eu optei em abrir o negócio mesmo.... Em um período de um ano, eu fiquei em um plano de negócio, até mesmo pra conhecer o público mesmo, evangélico.... Então nasceu essa ideia, ... foi uma sala dentro da igreja, e foi em caráter experimental. Então a gente foi estudando o mercado, analisando como tratar com fornecedor, como deveria ser a postura do meu cliente, e aí a gente foi trabalhar". (Empreendedora - Empresa 16).

Os relatos demonstram particularidades associadas ao surgimento da ideia para a criação do negócio. É possível observar, nos casos estudados e conforme ilustrado pelos casos 6 e 16, um certo padrão de envolvimento e socialização dos empreendedores em práticas e atividades desempenhadas cotidianamente no âmbito da igreja e/ou dos templos religiosos. O caso da empresa 16 é revelador nesse ponto. Ao fazer parte da igreja, a ideia para a criação do negócio nasce dentro do espaço religioso. Além disso, a socialização no contexto da igreja permitiu que o empreendedor conhecesse o público evangélico, e adquirisse experiências e conhecimentos sobre mercado, fornecedores e clientes. Nesse sentido, a participação ativa de empreendedores e empreendedoras no contexto específico da religião, com o envolvimento em atividades de igrejas, centros e templos, bem como a vivência e a prática religiosa, seja no âmbito individual, familiar e/ou social, constitui-se como elemento central de influência no surgimento da ideia para a criação do novo negócio.

Adicionalmente, a religião se posiciona como elemento que influi significativamente sobre as motivações para a abertura de empreendimentos, sobretudo daqueles que exploram o nicho da religiosidade através da comercialização de produtos e artigos religiosos.

"Eu acho que tudo tem seu tempo, porque é um trabalho que às vezes impede, é uma faculdade, alguma coisa. Então a gente sempre vai deixando aquele sonho pra uma hora que der. Aí de repente tudo deu certo e assim, coincidiu de falar 'não, vai ser agora, vamos abrir' e começamos a tomar essa iniciativa. Foi assim, um sonho que de repente aconteceu, sem esperar muito.... Eu acho que [a abertura da empresa] foi planejada pela espiritualidade.... É, uma missão talvez de levar, de divulgar a doutrina". (Empreendedora - Empresa 4).

"Eu acredito [que a livraria é uma missão]. Eu acredito que houve um trabalho preestabelecido, ... um trabalho predeterminado mesmo, ao ponto de hoje a gente ter [a empresa], da maneira como a livraria chegou até a mim". (Empreendedora - Empresa 5). 
"Além de ser o nosso meio de sobrevivência, [a empresa] também é o ... caminho que nós encontramos para chegar até Deus.... Esse trabalho é a cruz, é o sagrado, é o encontro com Deus, é a realização também, já que nós fizemos essa opção de trabalhar, servir a Deus através deste trabalho". (Empreendedor - Empresa 10).

“[A empresa] representa muito pra mim. Eu vejo ela realmente como uma missão ..., então não é simplesmente uma empresa. Eu acho assim, se alguém falasse pra mim que não eu não teria mais a livraria, seria como se tirasse uma parte da minha vida”. (Empreendedora - Empresa 13).

As motivações para a abertura de empresas no setor de artigos religiosos, nos casos estudados, revestem-se de elementos simbólicos associados à religião, envolvendo a ação de empreendedores estruturada a partir da exploração de recursos materiais e imateriais para a criação do novo negócio. Um fato que merece destaque é o de que, além de aspectos mercadológicos e econômicos, existem motivações ligadas a aspectos religiosos. Neste sentido, a fé, e a motivação por ela obtida para servir a Deus através do trabalho posicionam a intenção de abertura da empresa como um trabalho preestabelecido, predeterminado e planejado pela espiritualidade, configurando-se como uma espécie de missão, aqui vinculada à noção de chamado discutida por Weber (2001). Assim, a empresa seria a cruz, o sagrado, o encontro com Deus, a realização, revestindo o processo de criação de negócios no ramo de artigos religioso por aspectos que vão além de elementos puramente objetivos e racionais, normalmente vinculados ao fenômeno do empreendedorismo.

Adicionalmente, verifica-se que as falas antes mencionadas, enquanto representativas da realidade estudada, indicam motivações de natureza subjetiva, uma vez que a própria criação do negócio, segundo a narrativa dos entrevistados, seguiu elementos discursivos que se fazem presentes no âmbito das diferentes religiões. Neste sentido, e consoante à perspectiva exposta por Drakopoulou Dodd e Gotsis (2007), a religião opera sobre as motivações e as ações do sujeito empreendedor, influindo em sua propensão ao empreendedorismo.

\section{A religião enquanto oportunidade de negócio}

Ao mesmo tempo em que retoma e não desconsidera o papel desempenhado pelo sujeito empreendedor na configuração e no direcionamento de ações empreendedoras de abertura e desenvolvimento de organizações, a perspectiva do processo empreendedor envolve a questão da oportunidade de negócio, sua existência, descoberta, identificação e posterior exploração (Shane \& Venkataraman, 2000). Assim, abrem-se possibilidades tanto para a descoberta como para a criação de oportunidades de negócio, as quais alavancam a atividade empreendedora e geram espaço para o desenvolvimento econômico.

Como demonstrado no quadro teórico do artigo, o processo empreendedor é fortemente marcado por fatores de natureza individual, organizacional e/ou contextual. Por outro lado, a religião também atua como um elemento interveniente ao processo empreendedor. Conforme exposto por Drakopoulou Dodd e Gotsis (2007) e Dana (2009), as oportunidades definem e podem ser definidas pelo empreendedorismo religioso, abrindo perspectivas para o surgimento de novos negócios.

O conjunto de evidências discutidos anteriormente, sobre o papel desempenhado pelo agente empreendedor, reforça o potencial de transformação de uma ideia em oportunidade para a abertura de empresas no ramo de artigos religiosos, como pode ser constatado a seguir:

"Esse sonho de ter uma livraria espírita nasceu desde quando a gente entrou pro espiritismo ..., desde que a gente conheceu a doutrina.... A minha irmã, desde novinha, sempre interessou muito por leitura. E a gente assim, quando a gente entrou na doutrina espírita, ela já começou a ler muitos livros sobre a doutrina espírita. Aí ela foi criando uma gama de conhecimentos muito grande nesse setor.... Então a gente juntou esse conhecimento dela com os livros e a paixão pela doutrina espírita”. (Empreendedora - Empresa 4).

“A minha mãe trabalha com a espiritualidade há muitos anos, e quando eu era criança, ela falava que aqui no bairro deveria ter uma loja de umbanda. [Quando] eu voltei de São Paulo, eu voltei e fiquei sem emprego. Eu voltei em 1994, tentei uma coisinha ou outra, e aí acabei montando uma lojinha, lógico, bem humilde, bem simplesinha, e com o tempo ela foi crescendo". (Empreendedor - Empresa 8). 
"[A abertura da loja aconteceu] porque a gente faz parte de um centro espírita, e a gente tinha muita dificuldade em [encontrar produtos].... Era meio que monopolizado, ficava tudo na mão de uma pessoa só.... Tudo que a gente queria tinha que ser lá, o preço que ele queria. Gostando ou não do atendimento, você era obrigado a comprar dessa pessoa, porque não tinha outra opção". (Empreendedora - Empresa 20).

Consoante à perspectiva exposta por Shane e Venkataraman (2000), as oportunidades existem e podem ser descobertas e identificadas tanto no nível individual como no nível contextual. No nível do indivíduo, o conhecimento e a socialização no âmbito da religião novamente aparecem como características que marcam a experiência e a atuação do agente empreendedor, como pode ser observado nos casos das empresas 4 e 8 . Neste sentido, elementos como a posse de uma gama de conhecimentos muito grande no setor de artigos religiosos, a paixão pela doutrina espírita e o trabalho com a espiritualidade há muitos anos, fizeram com que os empreendedores visualizassem a oportunidade de abertura de empresas nesse ramo de atividade. Já no nível contextual, os casos 8 e 20 revelam a presença de aspectos mercadológicos, sobretudo a partir do espaço existente no mercado para a comercialização desses produtos. Dentro dessa perspectiva, ao enxergar a oportunidade do estabelecimento de atividade empresarial através da mercantilização de artigos de cunho religioso, os empreendedores associam suas intenções e suas atividades empreendedoras ao atendimento de uma demanda de mercado específica, ligada à religião.

Assim, observa-se que a existência, a descoberta e a identificação de oportunidades de negócio encontram-se imbricadas a aspectos individuais, à natureza da religião e ao contingente de seguidores de uma determinada doutrina religiosa, enquanto potencial mercado-alvo para a criação do empreendimento. A partir disso, podem ser verificadas evidências adicionais, vinculadas à presença de componentes da religião na exploração dessas oportunidades de negócio e nas diferentes motivações para a abertura dos empreendimentos para comercialização de produtos e artigos religiosos:

"Eu sempre quis trabalhar [com artigos religiosos]. Eu sempre ajudei em final de semana em evento, eu trabalho com jovem [na igreja], já coordenei na diocese um trabalho com jovem, represento um trabalho com jovem no Estado. Então, assim, eu sempre quis ter mais tempo pra trabalhar com isso. Então [a abertura da loja] foi pela fé, foi uma luz que Deus abriu no nosso caminho, uma porta. Eu conversei com a minha esposa e a gente decidiu: 'vamos aproveitar a oportunidade de abrir a loja'”. (Empreendedor - Empresa 1).

"Eu tinha a ideia de servir a Deus e encontrei também uma pessoa, que é minha esposa hoje, que também tinha a ideia de servir a Deus, só que nós tivemos a dúvida de como servir a Deus. Eu fui pro seminário, minha esposa também foi pro convento, pouquinho tempo, mas foi. Depois nós voltamos e vimos: 'nós podemos servir a Deus no mundo, trabalhando', né? E, há pouco tempo, apareceu a oportunidade da gente trabalhar com artigo religioso. Então aí veio a resposta que nós estávamos procurando: servir a Deus através do artigo religioso". (Empreendedor - Empresa 10).

Verifica-se que a exploração de oportunidades de negócio se reconfigura e se manifesta na abertura de empresas de cunho religioso. Os casos das empresas 1 e 10 demonstram o movimento que define o processo empreendedor. O surgimento da ideia, a descoberta e identificação de oportunidades de negócio, bem como o desejo do empreendedor em trabalhar nesse tipo de atividade, conduzem ao aproveitamento dessa oportunidade via criação do empreendimento, tida como uma luz que Deus abriu no caminho do empreendedor e possibilitada pela fé, ou ainda, como uma forma de servir a Deus no mundo, trabalhando..., através do artigo religioso. Neste sentido, abre-se espaço para a configuração do processo empreendedor em empresas de produtos e artigos religiosos, e para a percepção de possibilidades de abertura dessas empresas, aliando oportunidades de negócio, trabalho, empreendedorismo e religião, enquanto aspectos religiosos e organizacionais que influenciam e dinamizam esse processo.

\section{Os resultados do processo empreendedor}

Outro aspecto que merece destaque refere-se ao objetivo do negócio, o qual pode ser interpretado, em um primeiro momento, como fato gerador do processo empreendedor, posteriormente, como um resultado desse processo, configurando a evolução, o desenvolvimento e a própria condução das atividades de organizações que exploram o nicho da religiosidade. Verificou-se que, nos casos 
estudados, o objetivo final do lucro é associado a uma finalidade adicional, vinculada ao aspecto religioso:

\begin{abstract}
"A gente sempre buscou evangelizar, sempre quer estar evangelizando.... O nosso conceito... até a gente tem uma frasezinha que a gente usa também, é: 'Dê presentes que evangelizam'. Esse 'evangeliza' pra nós não é nem só no sentido assim: 'seja católico', não, [mas] no sentido mesmo de viver as virtudes do Cristo, do cristão, que é o que eu acho que é o principal”. (Empreendedor - Empresa 1).
\end{abstract}

\begin{abstract}
“A minha preocupação chama 'divulgação da doutrina', e eu levo isso a sério.... Graças a Deus, a minha parte eu estou fazendo, com muita seriedade.... Porque o meu ideal é a divulgação da doutrina. Eu tenho até atividades complementares pra ajudar a própria livraria, para que o livro esteja na mão até do assalariado.... Não sou uma instituição filantrópica, não carrego nome de filantropia, porque isso talvez até me daria direitos a mais, mas não, nunca usei desse subterfúgio, entendeu? O meu negócio é um ideal, entendeu? É fazer circular o livro o mais rápido possível". (Empreendedora - Empresa 5).
\end{abstract}

\begin{abstract}
"[Nosso objetivo] é evangelizar através de artigos religiosos. Então, a vocação nossa também é nossa missão de cristão do mundo.... Então a gente viu assim, como que casou [o nome da empresa] com a nossa missão.... É a mensagem, ... que tem a passagem bíblica que fala que: 'todo mundo [deve] enunciar o evangelho a toda criatura'. Então nós estamos anunciando a [mensagem] a toda criatura, nós até colocamos como slogan uma outra frase nossa assim: 'que a nossa missão, o nosso trabalho, é a missão de evangelizar". (Empreendedor - Empresa 10).
\end{abstract}

Nota-se que elementos como a busca da evangelização em empreendimentos de natureza católica (Empresa 1, Empresa 2, Empresa 7, Empresa 10, Empresa 11) e em empresas de artigos evangélicos (Empresa 15), bem como a divulgação da doutrina em empresas vinculadas ao espiritismo (Empresa 4, Empresa 5, Empresa 22), surgem como objetivo final do negócio. Observa-se, portanto, que a comercialização de artigos religiosos combina objetivos comerciais e econômicos a objetivos de natureza simbólica, estabelecendo princípios que orientam a ação dos empreendedores.

Tal fato, inclusive, corrobora a literatura sobre a relação entre empreendedorismo e religião, na medida em que permite identificar ações empreendedoras orientadas pela religiosidade presente em valores, motivações e movimentos de aproveitamento de oportunidades (Drakopoulou Dodd \& Gotsis, 2007). Além disso, tal constatação também expõe um desafio de interpretação, abrindo espaço para novas possibilidades de compreensão desse fenômeno pouco conhecido. A empresa 6 , nesse sentido, ilustra bem tal perspectiva. Ao afirmar que "cada mercadoria não é só a parte física, é também entendimento de Deus, conhecimento de Deus" (Empresa 6), e que o produto "tem um peso não só comercial, [mas] espiritual" ( Empresa 6), o empreendedor revela que a sua empresa seria um local não voltado apenas para o lucro, mas também para a divulgação de um "ideal" (Empresa 5), para oferecer ao cliente um produto marcado por uma espécie de experiência espiritual. Assim, seria possível difundir o conhecimento e o conteúdo religioso, cumprindo uma missão religiosa de doutrinamento, para seguir "abençoando a vida de outras pessoas" (Empresa 15).

\title{
Empreendedorismo religioso: síntese dos resultados
}

A análise integrada dos 22 casos estudados permite a identificação de evidências relevantes da manifestação de um fenômeno que pode ser caracterizado como empreendedorismo religioso. Elementos associados à religião estiveram presentes de maneira significativa no âmbito do processo empreendedor, envolvendo o surgimento da ideia para a abertura da empresa, a descoberta e a identificação de oportunidades de negócio, a exploração dessas oportunidades e o consequente processo de criação desses empreendimentos. Além disso, tal manifestação também pôde ser observada no âmbito das motivações dos empreendedores para a abertura das empresas e nos objetivos - comerciais e religiosos - presentes em sua atuação empresarial.

O conjunto de evidências presentes nos casos analisados permite observar a relação entre religião e empreendedorismo de uma forma ampla e complexa, expressa em elementos sociais, culturais e simbólicos. Neste cenário, a religião surge como um elemento que permite caracterizar a formação de um tipo particular de ação empreendedora. Situações como o comportamento e a ação do empreendedor 
religioso, a socialização desses agentes no contexto de suas religiões específicas, as motivações para a abertura das empresas, tais como a relação íntima entre a ação empreendedora e a questão espiritual, e a intenção adicional em comercializar produtos para a obtenção de lucro e, paralelamente, para a divulgação do conteúdo doutrinário da religião com o intuito de evangelização, corroboram para a caracterização da manifestação do empreendedorismo religioso nas organizações estudadas, em conformidade com as abordagens expostas por autores como Drakopoulou Dodd e Seaman (1998), Drakopoulou Dodd e Gotsis (2007), Dana (2009, 2010), Enoque, Borges, Borges, Almeida e Mariano (2014) e Zelekha et al. (2014).

\section{Conclusão}

O objetivo geral do presente trabalho consistiu em compreender as particularidades da manifestação do empreendedorismo religioso em empresas que nascem no contexto da religião e que comercializam artigos religiosos. A análise dos resultados permitiu verificar evidências de que a criação de negócios no ramo da religiosidade, marcada por aspectos como a identificação de oportunidades de negócio e sua exploração através da criação e abertura das empresas, é corroborada pela influência de diferentes elementos de natureza religiosa.

Com efeito, a ação do empreendedor de cunho religioso, enquanto um agente de empreendedorismo marcado pela influência doutrinária de sua religião de origem, estrutura-se a partir de elementos objetivos - relacionados à própria criação do negócio e à abertura da empresa - e subjetivos - associados ao comportamento e à ação do empreendedor, à sua socialização religiosa, às motivações para agir de forma empreendedora, ao relacionamento íntimo entre essas motivações e a questão espiritual, à missão de atuação no ramo de artigos religiosos e ao objetivo de divulgação da doutrina religiosa. Esses elementos, por sua vez, manifestam-se em um mesmo espaço e em um mesmo conjunto de situações através de uma relação dinâmica, revelando particularidades que não se fazem presentes em outras possibilidades de empreendedorismo.

Portanto, pode-se concluir que as evidências observadas nas relações entre empreendedorismo e religião corroboram para a configuração do empreendedorismo religioso. Este, por sua vez, constitui-se como um tipo particular de empreendedorismo, pouco explorado na literatura, fato que revela uma demanda por maiores elaborações teóricas para sua adequada compreensão. Diante disso, abre-se espaço para a investigação desse fenômeno diferenciado, que abarca nuances pouco consideradas na pesquisa sobre empreendedorismo, o que certamente auxiliaria na compreensão das particularidades que se fazem presentes em organizações marcadas pela relação entre empreendedorismo e religião.

Cabe ressaltar, neste momento, que a presente pesquisa apresenta algumas limitações. Primeiro, do ponto de vista teórico, o reduzido número de estudos sobre a relação entre empreendedorismo e religião, sobretudo no nível brasileiro, imprimiu desafios na formulação do quadro teórico articulado no artigo. Estudos futuros poderiam objetivar o desenvolvimento de perspectivas teóricas voltadas para a análise de empreendimentos de cunho religioso, levando em consideração, em suas elaborações, especificidades da realidade brasileira e do cenário religioso nacional. Segundo, do ponto de vista metodológico, alguns aspectos merecem consideração. Apesar da amplitude do número de casos estudados, ressalta-se que foi realizada uma entrevista com cada entrevistado. É possível que um segundo contato pudesse revelar novos elementos que relacionam empreendedorismo e religião nos casos pesquisados, o que certamente contribuiria para uma maior qualidade dos dados coletados. Além disso, as informações obtidas por meio das entrevistas não foram confrontadas com documentos para confirmação das datas e da sequência dos eventos relatados pelos entrevistados. Isso ocorreu, sobretudo, porque trata-se de pequenos empreendimentos e o registro e arquivo de informações sobre a história destes não consiste em prática comum ao grupo de pesquisados. Estudos futuros poderiam explorar, de um lado, abordagens quantitativas de investigação, procurando averiguar se as evidências empíricas destacadas neste trabalho podem ser observadas em outros contextos, e, de outro, diferentes métodos de pesquisa qualitativa, como, por exemplo, a etnografia, buscando compreender em profundidade o 
cotidiano desse tipo de organização e as diferentes possibilidades de influência da religiosidade sobre esses empreendimentos.

Por outro lado, o presente trabalho também apresenta contribuições importantes para o campo de estudos em empreendedorismo. Primeiro, como já mencionado ao longo do texto, o trabalho trata de uma realidade pouco conhecida no âmbito dos estudos em empreendedorismo e nos estudos organizacionais. Além disso, esta pesquisa lida com um contexto particular até mesmo para os estudos que procuraram articular a relação entre religião e empreendedorismo, uma vez que analisa casos de empresas que exploram o nicho da religiosidade, bastante interessantes na realidade brasileira, marcada pela pluralidade religiosa. Reforça essa contribuição o fato de que a própria religião se posiciona como motivação e oportunidade para a criação do negócio, uma variável pouco explorada no âmbito do campo de pesquisas em empreendedorismo e que merece maiores esforços de compreensão. Ainda merece destaque o fato de que este trabalho abre possibilidade para a exploração de aspectos subjetivos no campo do empreendedorismo, deixando de lado quadros teóricos influenciados por correntes econômicas e/ou comportamentais que valorizam e reforçam o discurso e a análise restrita a empresas orientadas exclusivamente pela lógica capitalista. Por fim, estas contribuições suscitam novos estudos sobre a configuração do empreendedorismo religioso, sobre a criação de empresas no nicho da religiosidade, sobre a religião enquanto oportunidade de negócios, e sobre como a religião influencia a gestão dos empreendimentos, demonstrando um campo fértil para novas pesquisas em empreendedorismo e estudos organizacionais.

\section{Agradecimentos}

Agradecemos à Fundação de Amparo à Pesquisa do Estado de Minas Gerais (FAPEMIG), pelo financiamento ao projeto de pesquisa que originou o presente artigo (Processo $n^{\circ}$ APQ01568-10).

\section{Referências}

Audretsch, D. B., \& Meyer, N. S. (2009, July). Religion, culture and entrepreneurship in India. Proceedings of the International Public Affairs Conference, Indianapolis, IN, 1.

Bardin, L. (2004). Análise de conteúdo (3a ed.). Lisboa: Edições 70.

Becker, O. S., \& Woessmann, L. (2009). Was Weber wrong? A human capital theory of protestant economic history. The Quarterly Journal of Economics, 124(2), 531-596. doi: 10.1162/qjec.2009.124.2.531

Buenstorf, G. (2007). Creation and pursuit of entrepreneurial opportunities: an evolutionary economics perspective. Small Business Economics, 28(4), 323-337. doi: 10.1007/s11187-006-9039-5

Busenitz, L. W., West, G. P., III, Shepherd, D., Nelson, T., Chandler, G. N., \& Zacharakis, A. (2003). Entrepreneurship research in emergence: past trends and future directions. Journal of Management, 29(3), 285-308. doi: 10.1016/S0149-2063_03_00013-8

Bygrave, W. (2008). The entrepreneurship paradigm revisited. In H. Neergard \& J. P. Ulhoi (Orgs.), Handbook of qualitative research methods in entrepreneurship (Vol. 1, Cap. 2, pp. 17-48). Cheltenham: Ed. Elgar.

Carswell, P., \& Rolland, D. (2004). The role of religion in entrepreneurship participation and perception. International Journal of Entrepreneurship and Small Business, 1(3/4), 280-286. doi: 10.1504/IJESB.2004.005659 
Carswell, P., \& Rolland, D. (2007). Religion and entrepreneurship in New Zealand. Journal of Enterprising Communities: People and Places in Global Economy, 1(2), 162-174. doi: $10.1108 / 17506200710752584$

Certo, S. T., \& Miller, T. (2008). Social entrepreneurship: key issues and concepts. Business Horizons, 51(4), 267-271. doi: 10.1016/j.bushor.2008.02.009

Collins, R. (1997). An Asian route to capitalism: religious economy and the origins of self-transforming growth in Japan. American Sociological Review, 62(6), 843-865.

Cornwall, J. R., \& Naughton, M. J. (2003). Who is the good entrepreneur? An exploration within the catholic social tradition. Journal of Business Ethics, 44(1), 61-78. doi: 10.1023/A:1023294626341

Dana, L.-P. (2009). Religion as an explanatory variable for entrepreneurship. The International Journal of Entrepreneurship and Innovation, 10(2), 87-99. doi: 10.5367/000000009788161280

Dana, L.-P. (2010). Entrepreneurship and religion. Cheltenham: Ed. Elgar.

Denzin, N. K., \& Lincoln, Y. S. (2008). The landscape of qualitative research. London: Sage Publications.

Denzin, N. K., \& Lincoln, Y. S. (2011). Introduction: the discipline and practice of qualitative research. In N. K. Denzin \& Y. S. Lincoln (Eds.), The sage handbook of qualitative research (Vol. 1, Cap. 1, pp. 1-20). London: Sage Publications.

Dougherty, K. D., Griebel, J., Neubert, M. J., \& Park, J. Z. (2013). A religious profile of American entrepreneurs. Journal of the Scientific Study of Religion, 52(2), 401-409. doi: 10.1111/jssr.12026

Drakopoulou Dodd, S. D., \& Gotsis, G. (2007). The interrelationships between entrepreneurship and religion. The International Journal of Entrepreneurship and Innovation, 8(2), 93-104. doi: $10.5367 / 000000007780808066$

Drakopoulou Dodd, S. D., \& Seaman, P. T. (1998). Religion and enterprise: an introductory exploration. Entrepreneurship: Theory \& Practice, 23(1), 71-86.

Eckhardt, J. T., \& Shane, S. A. (2003). Opportunities and entrepreneurship. Journal of Management, 29(3), 333-349. doi: 10.1177/014920630302900304

Eisenhardt, K. M. (1989). Building theories from case study research. Academy of Management Review, 14(4), 532-550. doi: 10.5465/AMR.1989.4308385

Eisenhardt, K. M., \& Graebner, M. E. (2007). Theory building from cases: opportunities and challenges. Academy of Management Journal, 50(1), 25-32. doi: 10.5465/AMJ.2007.24160888

Enoque, A. G., Borges, A. F., Borges, J. F., Almeida, L. L. S., \& Mariano, V. P., Filho (2014). Configurações do empreendedorismo religioso: um estudo na cidade de Ituiutaba - Minas Gerais. In C. M. I. Katrib \& T. C. Coimbra (Orgs.), Releituras da cidade: memória, história e identidade (Vol. 1, Cap. 5, pp. 59-71). Uberlândia: Editora da Universidade Federal de Uberlândia.

Filion, L. J. (1999b). Diferenças entre sistemas gerencias de empreendedores e operadores de pequenos negócios. Revista de Administração de Empresas, 39(4), 6-20. Recuperado de http://www.scielo.br/pdf/rae/v39n4/v39n4a02.pdf. doi: 10.1590/S0034-75901999000400002

Filion, L. J. (1999a). Empreendedorismo: empreendedores e proprietários-gerentes de pequenos negócios. Revista de Administração, 39(4), 5-28.

Gaskell, G. (2010). Entrevistas individuais e grupais. In M. W. Bauer \& G. Gaskell (Orgs.), Pesquisa qualitativa com texto, imagem e som: um manual prático (pp. 64-89). Petrópolis: Vozes. 
Ghoul, W. A. (2010). Islam and entrepreneurship. In L.-P. Dana (Org.), Entrepreneurship and religion (Vol. 1, Cap. 12, pp. 269-280). Cheltenham: Ed. Elgar.

Gomes, A. F., Lima, J. B., \& Cappelle, M. C. A. (2013). Do empreendedorismo à noção de ações empreendedoras: reflexões teóricas. Alcance, 20(2), 203-220. doi: 10.14210/alcance.v20n2.p203-220

Grégoire, D. A., Noël, M. X., Déry, R., \& Béchard, J.-P. (2006). Is there conceptual convergence in entrepreneurship research? A co-citation analysis of frontiers of entrepreneurship research, 19812004. Entrepreneurship: Theory \& Practice, 30(3), 333-373. doi: 10.1111/j.15406520.2006.00124.x

Haber, S., \& Reichel, A. (2007). The cumulative nature of the entrepreneurial process: the contribution of human capital, planning and environment resources to small business performance. Journal of Business Venturing, 22(1), 119-145. doi: 10.1016/j.jbusvent.2005.09.005

Hayton, J. C., George, G., \& Zahra, S. A. (2002). National culture and entrepreneurship: a review of behavioral research. Entrepreneurship: Theory \& Practice, 26(4), 33-52.

Hessels, J., Gelderen, M. van, \& Thurik, R. (2008). Entrepreneurial aspirations, motivations, and their drivers. Small Business Economics, 31(3), 323-339. doi: 10.1007/s11187-008-9134-x

Jack, S. L., \& Anderson, A. R. (2002). The effects of embeddedness on the entrepreneurial process. Journal of Business Venturing, 17(5), 467-487. doi:10.1016/S0883-9026(01)00076-3

Jackson, J. J., \& Konz, G. N. P. (2006). Spirituality and entrepreneurs. Journal of Management, Spirituality \& Religion, 3(3), 242-257. doi: 10.1080/14766080609518628

Kauanui, S. K., Thomas, K. D., Sherman, C. L., Waters, G. R., \& Gilea, M. (2008). Exploring entrepreneurship through the lens of spirituality. Journal of Management, Spirituality \& Religion, 5(2), 160-189. doi: 10.1080/14766080809518698

Light, I. (2010). The religious ethic of the protestant ethnics. In L.-P. Dana (Org.), Entrepreneurship and religion (Vol. 1, Cap. 6, pp. 168-183). Cheltenham: Ed. Elgar.

Lima, J. B. (2010). Ações empreendedoras e práticas de pesquisa em empreendedorismo. In F. Gimenez, J. M. Ferreira, \& S. C. Ramos (Orgs.), Empreendedorismo e estratégia de empresas de pequeno porte (Vol. 1, Cap. 3, pp. 25-40). Curitiba: Editora Champagnat.

Martes, A. C. B. (2010). Weber e Schumpeter: a ação econômica do empreendedor. Revista de Economia Política, 30(2), 254-270. Recuperado de http://www.scielo.br/pdf/rep/v30n2/05.pdf. doi: 10.1590/S0101-31572010000200005

Martes, A. C. B., \& Rodriguez, C. L. (2004). Afiliação religiosa e empreendedorismo étnico: o caso dos brasileiros nos Estados Unidos. Revista de Administração Contemporânea, 8(3), 117-140. Recuperado de http://www.scielo.br/pdf/rac/v8n3/v8n3a07.pdf. doi: 10.1590/S141565552004000300007

Martinelli, A. (1995). Entrepreneurship and management. In N. J. Smelser \& R. Swedberg (Orgs.), The handbook of economic sociology (Vol. 1, Cap. 19, pp. 476-503). Princeton: Princeton University Press.

McMullen, J. S., Plummer, L. A., \& Acs, Z. J. (2007). What is an entrepreneurial opportunity? Small Business Economics, 28(4), 273-283. doi: 10.1007/s11187-006-9040-Z

Moroz, P. W., \& Hindle, K. (2012). Entrepreneurship as a process: toward harmonizing multiple perspectives. Entrepreneurship: Theory \& Practice, 36(4), 781-818. doi: 10.1111/j.15406520.2011.00452.x 
Nassif, V. M. J., Ghobril, A. N., \& Silva, N. S. (2010). Understanding the entrepreneurial process: a dynamic approach. Brazilian Administration Review, 7(2), 213-226. doi: 10.1590/S180776922010000200007

Neergaard, H., \& Ulhøi, J. P. (2007). Introduction: methodological variety in entrepreneurship research. In H. Neergaard \& J. P. Ulhøi (Eds.), Handbook of qualitative research methods in entrepreneurship (Vol. 1, Cap. 1, pp. 1-16). London: Sage Publications.

Nekka, H., \& Fayolle, A. (2010). Muslim entrepreneurs in France. In L.-P. Dana (Org.), Entrepreneurship and religion (Vol. 1, Cap. 14, pp. 296-312). Cheltenham: Ed. Elgar.

Patton, M. (1990). Qualitative evaluation and research methods. Beverly Hills: Sage.

Plummer, L. A., Haynie, J. M., \& Godesiabois, J. (2007). An essay on the origins of entrepreneurial opportunity. Small Business Economics, 28(4), 363-379. doi: 10.1007/s11187-006-9036-8

Rauch, A., Wiklund, J., Lumpkin, G. T., \& Frese, M. (2009). Entrepreneurial orientation and business performance: an assessment of past research and suggestions for the future. Entrepreneurship: Theory \& Practice, 33(3), 761-787. doi: 10.1111/j.1540-6520.2009.00308.x

Shane, S. (2000). Prior knowledge and the discovery of entrepreneurial opportunities. Organization Science, 11(4), 448-469. doi: 10.1287/orsc.11.4.448.14602

Shane, S., \& Venkataraman, S. (2000). The promise of entrepreneurship as a field of research. Academy of Management Review, 25(1), 217-226. doi: 10.5465/AMR.2000.2791611

Short, J. C., Ketchen, D. J., Jr., Shook, C. L., \& Ireland, R. D. (2010). The concept of "opportunity" in entrepreneurship research: past accomplishments and future challenges. Journal of Management, 36(1), 40-65. doi: 10.1177/0149206309342746

Silva, M. A. O. M., Gomes, L. F. A. M., \& Correia, M. F. (2009). Cultura e orientação empreendedora: uma pesquisa comparativa entre empreendedores em incubadoras no Brasil e em Portugal. Revista de Administração Contemporânea, 13(1), 57-71. Recuperado de http://www.scielo.br/pdf/rac/v13n1/a05v13n1.pdf. doi: 10.1590/S1415-65552009000100005

Souza, E. C. L. (2005). Empreendedorismo: da gênese à contemporaneidade. In E. C. L. Souza \& T. M. Guimarães (Orgs.), Empreendedorismo: além do plano de negócio (Vol. 1, Cap. 1, pp. 3-20). São Paulo: Atlas.

Tracey, P. (2012). Religion and organization: a critical review of current trends and future directions. The Academy of Management Annals, 6(1), 87-134. doi: 10.1080/19416520.2012.660761

Watson, T. J. (2013). Entrepreneurship in action: bringing together the individual, organizational and institutional dimensions of entrepreneurial action. Entrepreneurship \& Regional Development, 25(5/6), 404-422. doi: 10.1080/08985626.2012.754645

Weber, M. (2001). Ética protestante e o espírito do capitalismo. São Paulo: Pioneira.

Weinfeld, M. (2010). The Jewish sub-economy of Montreal. In L.-P. Dana (Org.), Entrepreneurship and religion (Vol. 1, Cap. 6, pp. 168-183). Cheltenham: Ed. Elgar.

Yin, R. K. (2005). Estudo de caso: planejamento e métodos (3a ed.). Porto Alegre: Bookman.

Zelekha, Y., Avnimelech, G., \& Sharabi, E. (2014). Religious institutions and entrepreneurship. Small Business Economics, 42(4), 747-767. doi: 10.1007/s11187-013-9496-6 


\section{Dados dos Autores}

Alex Fernando Borges

Rua 20, 1600, Campus do Pontal, Tupã, 38304-402, Ituiutaba, MG, Brasil. E-mail: alexfborges@ gmail.com

Alessandro Gomes Enoque

Rua 20, 1600, Campus do Pontal, Tupã, 38304-402, Ituiutaba, MG, Brasil. E-mail: alessandroenoque@ pontal.ufu.br

Jacquelaine Florindo Borges

Av. João Naves de Ávila, 2121. Campus Santa Mônica, Santa Mônica, Caixa Postal 593, 38408-100, Uberlândia, MG, Brasil.

E-mail: jac.borges@uol.com.br

Lorrana Laila Silva de Almeida

Rua 20, 1600, Campus do Pontal, Tupã, 38304-402, Ituiutaba, MG, Brasil. E-mail: lorranalaila.adm@ bol.com.br 